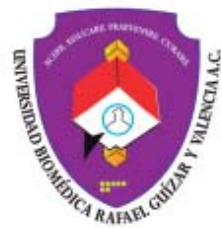

Vol. 8, Núm. 2

\title{
Clasificaciones y técnicas para evaluar lesiones del pie diabético. Recomendaciones: Parte 1 de 5
}

\author{
Classifications and techniques for evaluating diabetic foot \\ injuries. Recommendations: Part 1 of 5
}

Miguel Ángel Rodríguez Castellanos, ${ }^{*}$ Francisco Aguilar Rebolledo ${ }^{\ddagger}$

\section{RESUMEN}

Introducción: Las lesiones que se producen en el pie en los pacientes con diabetes mellitus tipo 2 (DM) son consecuencia de las complicaciones de la propia enfermedad. Objetivo: Conocer el abordaje correcto del pie diabético. Desarrollo: Las lesiones constituyen una de las fuentes más importantes de morbimortalidad en el orbe, sobre todo por el control inadecuado de la diabetes mellitus y el desconocimiento en el manejo de las úlceras del pie. Las situaciones psicosociales y de salud constituyen un factor que incide en el manejo y la prevención, que en algunos casos representa una causal grave, ya que los costos para su atención son altos. Conclusiones: Las personas con diabetes mellitus tienen entre $20-30 \%$ más riesgo de sufrir una amputación que las personas sin diabetes mellitus; esta epidemiología supone un grave problema para la salud pública y los recursos económicos empleados en salud.

Palabras clave: Pie diabético, diabetes mellitus tipo 2, úlcera, técnicas, abordaje manejo, recomendaciones.

\section{ABSTRACT}

Introduction: The lesions that occur in the foot in patients with type 2 diabetes mellitus (DM) are a consequence of the complications of the disease itself. Objective: To know the correct approach to the diabetic foot. Development: They constitute one of the most important sources of morbidity and mortality in the world, especially due to the inadequate control of diabetes mellitus, and the lack of knowledge in the management of foot ulcers. Psychosocial and health situations constitute a factor that affects management and prevention, which in some cases represents a serious cause since the costs for their care are high. Conclusions: People with diabetes mellitus have a 20-30\% higher risk of suffering an amputation than people without diabetes mellitus; this epidemiology represents a serious problem for public health and the economic resources used in health.

Keywords: Diabetic foot, type 2 diabetes mellitus, ulcer, techniques, management approach, recommendations.

\section{* Cirugía vascular, ISSSTE, Xalapa, Veracruz. \\ ${ }^{*}$ Rector de la Universidad Biomédica Rafael Guízar y Valencia (UNIBIO), Xalapa, Veracruz.

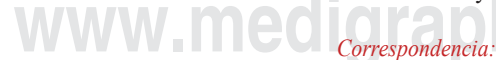 \\ Rector Acad. Dr. M. en C. Francisco Aguilar Rebolledo \\ Universidad Biomédica Rafael Guízar y Valencia. \\ Ángel Garrido No. 2, Colonia Represa del Carmen, CP: 91050, Xalapa, Veracruz, México. \\ E-mail: fran_aguilar_invest@yahoo.com.mx \\ Recibido: 15-09-2021. Aceptado: 07-11-2021.}

Citar como: Rodríguez CMÁ, Aguilar RF. Clasificaciones y técnicas para evaluar lesiones del pie diabético. Recomendaciones: Parte 1 de 5. Plast Restaur Neurol. 2021;8 (2): 102-109. https://dx.doi.org/10.35366/103090 


\section{INTRODUCCIÓN}

Las lesiones que se producen en el pie en los pacientes con diabetes mellitus (DM) son consecuencia de las complicaciones de la propia enfermedad y constituyen una de las fuentes más importantes de morbimortalidad en el orbe, sobre todo por el control inadecuado de la DM y el desconocimiento en el manejo de las complicaciones en el pie.

Los efectos de la enfermedad sobre el pie diabético son devastadores tanto en México como en Estados Unidos y constituyen $80 \%$ de las amputaciones no traumáticas en todos los países que tienen alta prevalencia de la enfermedad. Las situaciones psicosociales y de salud constituyen un factor que incide en el manejo y la prevención, que en algunos casos representa una causal grave, ya que los costos para su atención son altos. Las personas con DM tienen entre 20-30\% más riesgo de sufrir una amputación que las personas sin DM; la epidemiología lo ubica como un problema grave para la salud pública y los enormes recursos económicos empleados en salud. ${ }^{1}$

La DM es uno de los problemas sanitarios que más ha crecido en los últimos años, calculándose que duplica su prevalencia cada 10 años. El crecimiento elevado repercute en los costos, en el diagnóstico, manejo, tratamiento y sobre todo en la prevención. El pie diabético es una de las complicaciones más graves de la DM, se acompañan de varias alteraciones de tipo neuropático, vascular y mixto, además de la neuroartropatía de Charcot, las úlceras plantares, osteomielitis y, por último, la desafortunada amputación..$^{1,2}$

Lo paradójico es que $80 \%$ de las amputaciones por pie diabético pueden prevenirse con una atención temprana y un tratamiento oportuno. La atención pronta y adecuada, una clasificación clara que refleje el pronóstico y la gravedad del problema, serán factores decisivos para los buenos resultados. Realizar la referencia a un centro con mayores recursos humanos y técnicos detendrá la evolución de las potenciales complicaciones. Si el proceso infeccioso ya está agregado dentro de la úlcera, y ésta evoluciona hacia la gravedad, el riesgo potencial de perder la extremidad se compromete. ${ }^{3}$

«Después de perder una extremidad ya nada es igual»

Los tres factores fisiopatológicos que condicionan las lesiones del pie y que lo pueden llevar a la amputación de una extremidad son:

1. La neuropatía

2. La úlcera

3. La infección
Se suman como colaterales los cuidados y tratamientos inadecuados, además de que en $40 \%$ de los casos se asocia a enfermedad vascular periférica (EVP). ${ }^{4}$ Esto permite que se concentren las fuerzas de descarga de peso y aumente la presión del pie. En un pie con neuropatía, que no siente y no identifica tempranamente el problema por la insensibilidad causada por la neuropatía sensorial, conduce a la úlcera, la potencial infección y el riesgo de una desafortunada amputación parcial o total.

\section{Definición de pie diabético o síndrome de pie diabético}

Cuando hablamos de pie diabético infectado, la úlcera puede ser de origen neuropático, isquémico o mixto. Puede o no estar asociada a infección de tejidos blandos, superficiales o profundos y abarcar el músculo extendiéndose hasta el hueso y produciendo

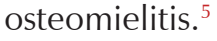

Cada una de estas alteraciones puede acompañar al pie diabético y contribuye en grado variable a la producción, prolongación del periodo de regeneración de la úlcera y la evolución hacia la cronicidad. Por lo tanto, la complicación del pie diabético queda mejor englobada dentro de un síndrome con distintas condiciones patológicas que requieren diferentes abordajes, generalmente multidisciplinarios, con tratamientos distintos y con pronósticos diferentes.

Al tratar de integrar el concepto de pie diabético como un síndrome debe englobar no sólo la úlcera como un proceso infeccioso en un pie con complicaciones vasculares, hemodinámicas e inmunológicas, sino incluyendo las características morfológicas como alteraciones anatómicas y/o funcionales que ocurren en los pies en personas con diabetes como consecuencia de su enfermedad metabólica (Figura 1).

La alteración del pie debe considerar las alteraciones estructurales, la sobrecarga de peso y el riesgo que existe para lesionarse con un zapato inadecuado que condiciona un trauma repetido dentro de un pie insensible por neuropatía autonómica. Teóricamente podemos imaginar cómo este tipo de concentración de fuerzas anormales inciden sobre una superficie frágil por el daño sensorial, autonómico y somático del pie, causando una respuesta inflamatoria local, isquemia tisular local, destrucción del tejido local, formación de grietas, ulceración y potencial infección. ${ }^{6}$

Para una definición práctica, sencilla y que resulte de utilidad el concepto de pie diabético debe ampliarse como síndrome de pie diabético y debe incluir el pie en riesgo, el pie con úlcera, el pie complicado y el pie 


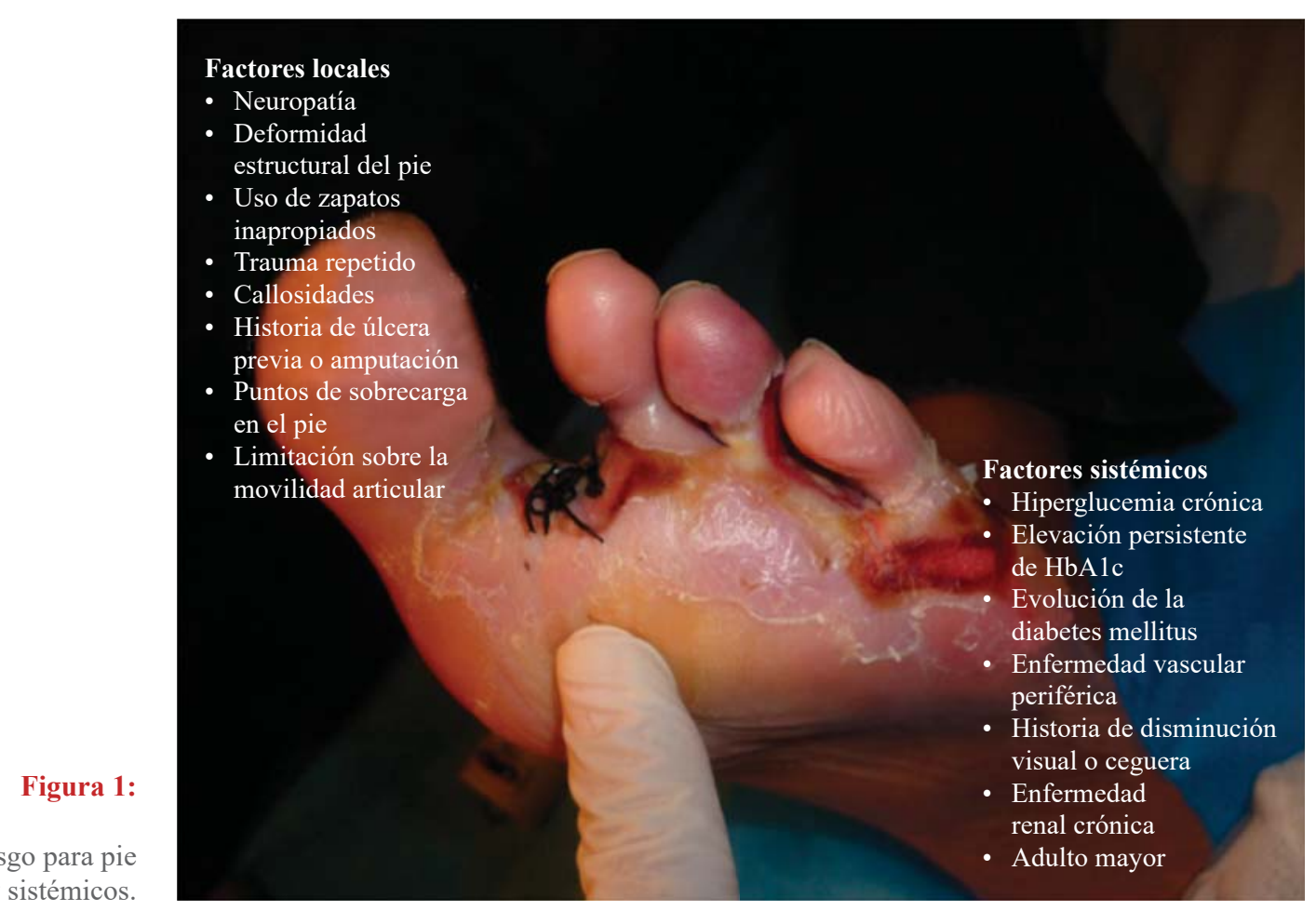

con amenaza para preservar la extremidad. Por tanto, es importante conocer la clasificación o las clasificaciones para describir y ubicar en su justa descripción las úlceras en el pie diabético que incidirán en el pronóstico de su curación.

En los últimos años, ha existido un gran interés de los médicos y profesionales de la biomedicina por adquirir herramientas oportunas para un buen abordaje de pie diabético. La alta tasa de prevalencia de úlceras diabéticas se ha convertido en el día a día para cualquier médico de primer contacto y/o especialista. Por lo que es crucial que conozcan lo elemental de lo que en medicina llamamos «la razón suficiente» para el desarrollo de una úlcera diabética.

La definición intenta ser lo más completa posible, sin embargo, es necesario incluir dentro del síndrome de pie diabético el pie en riesgo, el pie diabético con callos, grietas y úlceras pequeñas con o sin infección.

De todo ello, su definición no es sencilla, pero debe intentarse:

«Es una complicación de los pacientes con DM de etiología neuropática inducida por hiperglucemia crónica y sostenida y en la que puede coexistir isquemia. Se requiere para su desarrollo el trauma repetido del pie, habitualmente con daño estructural, cuya consecuencia es lesión a la piel afectada por neuropatía autonómica; dando lugar a la formación de la úlcera. Por otro lado, las condiciones de inmunosupresión de los pacientes con Diabetes Mellitus (DM) dan lugar a un terreno propicio para el desarrollo de las úlceras, además de la dificultad que produce para la cicatrización de la misma». ${ }^{7}$

\section{SÍNDROME DE PIE DIABÉTICO CON ÚLCERA}

El pie diabético ulcerado o con lesión requiere tomar en cuenta las características relacionadas con la enfermedad de base, por ejemplo:

1. Años de evolución de la DM.

2. Complicaciones de la DM que contribuyen al pronóstico.

3. Características de la úlcera y lesión: profundidad, tamaño, bordes, infección, exudados, necrosis, epitelización, número de úlceras.

4. Características estructurales del pie afectado: neuropatía motora, sensorial y autonómica.

5. Cambios vasculares: cambios de coloración en la piel, temperatura, dolor en la extremidad, atrofia, debilidad muscular y claudicación intermitente (Figura 2). 


\section{CONSIDERACIONES RELACIONADAS CON EL ESTADO METABÓLICO, NUTRICIOLÓGICO E INMUNOLÓGICO PARA LA CURACIÓN DE LA ÚLCERA}

Para tratarlas de la mejor manera posible y así reducir las dramáticas consecuencias de la enfermedad que pueden ser la desafortunada amputación. ${ }^{8}$

La presencia de úlceras y el manejo exitoso de las mismas es uno de los paradigmas más importantes para el manejo dentro del terreno de la investigación actual y permanece aún como un problema clínico con un futuro promisorio.

Los factores de crecimiento, neurotransmisores y péptidos con efectos vasoactivos sobre la micro- y macrovasculatura constituyen los principales detonantes del daño de la úlcera sobre los tejidos vecinos.

Disminuir el estrés oxidativo favorecerá a la angiogénesis y la vasorrelajación, mejorando la biodisponibilidad de nutrientes y oxígeno del tejido afectado. Éstos, entre otros, son los principales procesos patológicos asociados al riesgo de la úlcera. Por lo tanto, este enfoque resulta de gran importancia para brindar un tratamiento adecuado, adoptar medidas preventivas e identificar el pie en riesgo.

El estrés oxidativo y los radicales libres de oxígeno con una DM parcialmente controlada detona la dificultad en la biodisponibilidad de los factores que preevienen el daño tisular, al sistema vascular y el daño al DNA y las proteínas.

Para ello enumeraremos las clasificaciones más útiles, prácticas y sencillas para realizar un tratamiento oportuno y prevenir dentro de lo posible las desafortunadas amputaciones. ${ }^{9}$

\section{OBJETIVOS Y ESPECIFICACIONES DE LAS CLASIFICACIONES}

Se pueden utilizar principalmente de tres maneras:

1. Atención clínica de rutina

2. Investigación

3. Prevención

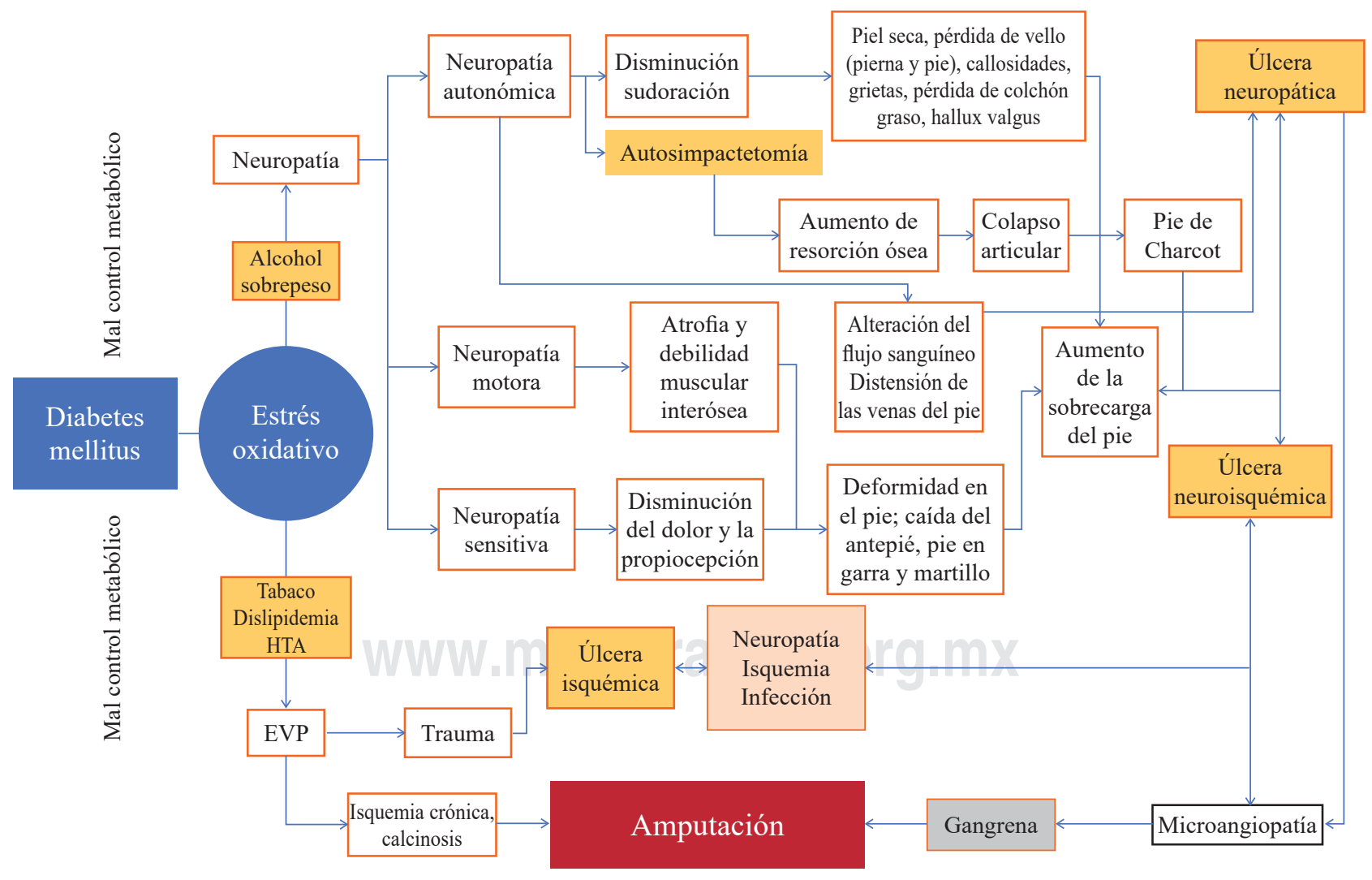

Figura 2: Integración de la etiología y fisiopatología del pie diabético. HTA = hipertensión arterial, EVP = enfermedad vascular periférica. 
El primero se utiliza en la valoración del paciente, mientras que la segunda y tercera se ocupa en grupos de pacientes, obteniendo los conocimientos ya descritos o nuevos, y proporcionándolos a los médicos, a los pacientes y a sus familiares para sus cuidados.

Particular atención requiere el analisis de la función cardiovascular, complementando una radiografía del tórax y un electrocardiograma para descartar complicaciones macro-vasculares. ${ }^{10}$

\section{Atención clínica}

Consiste en facilitar la recopilación de la información y comunicarla entre el médico o profesional de la salud y el paciente. El uso de una clasificación tendría beneficio adicional, ya que se puede tratar con mayor precisión el problema, incluye una adecuada valoración de las lesiones de la úlcera del pie y, por ende, la elección de tratamientos oportunos. ${ }^{11}$

\section{Investigación clínica}

Utilizar una clasificación en investigación sirve para identificar grupos de lesiones de características similares para incluirlas en estudios prospectivos, transversales y controlados. Sin embargo, la clasificación nos ayudará a identificar los casos más apropiados de un grupo y básicamente resaltar de manera oportuna su acción en bien del paciente. Esto refleja que las clasificaciones para enseñanza, en esencia, deben ser para todos los casos y deben ser conocidas por todos los médicos que tratan pacientes con DM, constituyendo una obligación dentro de su preparación profesional, de lo contrario se caerá en una negligencia médica por falta de preparación, la cual puede ser subsanada asistiendo a cursos, diplomados, congresos o estancias en unidades especializadas en la atención a pacientes con úlceras. ${ }^{12}$

\section{Autoenseñanza clínica}

El objetivo de la enseñanza clínica varía desde simples conteos de casos (por ejemplo: remisiones, números de casos de osteomielitis, incidencia de amputación) hasta búsqueda de correlación entre diferentes tipos de úlceras y su evolución. El objetivo será la comparación. Se deberá tomar en cuenta que las poblaciones sean semejantes, debido a que los grupos estudiados idealmente son numerosos. La aplicación de cuestionarios siempre deberá tener preguntas simples, claras y fáciles de comprender. ${ }^{13}$

\section{ASPECTOS FÁCILES Y DIFÍCILES DEL USO DE ALGUNAS CLASIFICACIONES}

La Universidad Biomédica Rafael Guízar y Valencia (UNIBIO) emitió el decálogo de recomendaciones de atención adecuada en úlceras del pie:

1. Establecer la etiología o etiologías de la úlcera.

2. Medición del tamaño.

3. Establecer su profundidad y determinar las estructuras afectadas superficiales o profundas.

4. Identificar las características del lecho ulceroso, microambiente, exudado, tipo de exudado.

5. Extensión de la celulitis, signos inflamatorios del tejido vecino a la úlcera: calor, rubor, cambios de color.

6. Características del olor.

7. Presencia de necrosis, número de úlceras, número de islas de epitelios y trayectos fistulosos.

8. Valorar el tejido alrededor de la úlcera para identificar la presencia de infección, edema, celulitis, abscesos o cambios de coloración.

9. Definir, de acuerdo a los parámetros generales, si la infección se ha extendido o ya es sistémica o se mantiene local.

10. Identificar el componente arterial realizando el examen vascular.

La revisión sistemática de estos pasos y su descripción minuciosa constituyen los estándares elementales para su clasificación.

Las clasificaciones no siempre son necesarias, pero siempre son útiles y requieren ser de fácil compresión, fáciles de recordar y universalizarse para usar el mismo lenguaje entre los profesionales implicados.

La mayoría de las clasificaciones que existen no recogen todos los aspectos, pero precisamente parte de nuestro trabajo es que puedan ser mejoradas siempre. ${ }^{8,11-14}$

\section{MOMENTO DE LA CLASIFICACIÓN}

\section{Primer paso}

\section{Cuestionamientos esenciales para valorar la úlcera del pie}

Recomendamos el uso de estas preguntas y observaciones que ayudarán a conocer con precisión paso a paso las condiciones de la úlcera; las primeras cuatro integran un gran valor descriptivo y las cuatro finales están relacionadas al pronóstico. 
1. ¿Dónde está localizada la úlcera? La localización de la úlcera y su causa van de la mano. Por lo general, las úlceras sobre la porción del antepié son causadas por la presión constante de la sobrecarga de peso asociadas generalmente a calzado justado; mientras que las úlceras del retropié son causadas por presiones repetidas de moderada intensidad que progresan durante la deambulación.

2. ¿Qué tamaño tiene la úlcera? El tamaño de las úlceras juega un papel importante para determinar la duración de su curación. Todas las úlceras deben ser medidas trazando lo largo y lo ancho o colocando una malla de acetato estéril que se cubre cada vez que queremos ver la evolución. Es un instrumento estéril y se puede emplear para realizar fotografías digitales y con la imagen J valorar el porcentaje progresivo de la curación.

3. ¿Qué contiene la base de la úlcera (el lecho ulceroso)? Cuando se describe el lecho de la úlcera se deben utilizar términos sencillos y claros que todo mundo pueda comprender, tales como:

a. Granular-granulación, epitelio-epitelización, fibroso-fibrótico.

a.1. Úlcera con necrosis seca y/o húmeda.

a.2. Bordes: límite, regular anfractuoso, superficial-profundo.

a.3. Exudado seroso, seropurulento, hemático y/o serohemático.

a.4. Color: puede ser color café, rojo, violáceo, sanguinolento o combinado.

a.5. Olor: puede ser intenso, fétido, putrefacto o inodoro.

4. ¿Qué características tienen los márgenes? Le llamamos márgenes de la úlcera a los bordes, los cuales son desbridados para permitir la granulación de las superficies subcuticulares que dan lugar al epitelio que permite la cicatrización normal. Sin embargo, es inadecuado desbridar inoportunamente cuando se realiza sobre una úlcera causada por sobrecarga. Ya que en estos casos, en particular los bordes, tienen un efecto de protección para la propagación de las bacterias, es decir, que ayuda a la matriz de la úlcera para detener la migración bacteriana. Las cicatrices impiden la cicatrización. Aquí lo más apropiado es desbridar, quitar cicatrices y dejar libres los bordes de sobrecarga.

Por otro lado, los márgenes o bordes de las úlceras pueden clasificarse como indeterminados, adheren- tes, macerados y como no viables. Los bordes de las úlceras sirven también para involucrarse dentro de las clasificaciones, como la de Wagner y San Antonio al referirse como bordes profundos, bordes infectados, bordes con isquemia, bordes en playa, en barranco o irregulares.

5. ¿Es úlcera única o múltiple? Las úlceras pueden ser únicas o múltiples. Pueden confluir o pueden estar separadas. Algunas pueden presentar algunos avances en la curación y otras tener atraso en la curación y cierta tendencia a la cronicidad. Por lo tanto, en el contexto del pie debe describirse cada una de ellas y las condiciones en las que se encuentran para establecer el pronóstico de manera independiente.

6. ¿Qué profundidad tiene? Aquí debemos introducir el término de la participación de las estructuras y tejidos involucrados; es posible que la profundidad contribuya con el tiempo de curación de las úlceras, habitualmente es importante la profundidad dentro de la clasificación. Asimismo, los grados de la úlcera de acuerdo a la profundidad. ${ }^{14}$

Grado 0: representan un sitio postulceroso.

Grado 1: las úlceras son superficiales a través de la epidermis, dermis, pero no penetran a los tendones, cápsulas o hueso.

Grado 2: las úlceras penetran a los tendones o a la cápsula articular.

Grado 3: las úlceras penetran al hueso o dentro de la articulación. Este grado se conoce como úlcera con osteomielitis.

7. ¿Está infectada? La definición de que el hueso o los tejidos blandos están infectados no es fácil. Uno puede sospecharlo por la clínica y corroborarlo a través de los exámenes de laboratorio y los cultivos con antibiograma. Los síntomas subjetivos son los que integran no sólo el grado de la infección, sino el tipo de gérmenes involucrados. Por ejemplo, Pseudomona aeruginosa tiene un olor fétido característico. La génesis de la infección, su diagnóstico y resolución son temas que continúan aún por resolverse (Figura 3).

8. ¿Tiene isquemia? La identificación de la isquemia con pies fríos, claudicación intermitente, dolor a la marcha, sobre todo en pendientes, el cual se exacerba progresivamente, son datos clínicos de gran importancia para evaluar la úlcera. Las úlceras isquémicas tienen una duración mucho más larga para su curación comparadas con sólo aquellas que son neuropáticas (Figura 4). 
Figura 3:

Pie diabético infectado.

A) Úlcera en la base de

desarticulación de tercero, cuarto y quinto ortejo, bordes

en barranco, secreción purulenta y área de necrosis en la base. B) Úlcera en el dorso con bordes en playa con secreción amarillenta y fibrina que entorpece la epitelización.
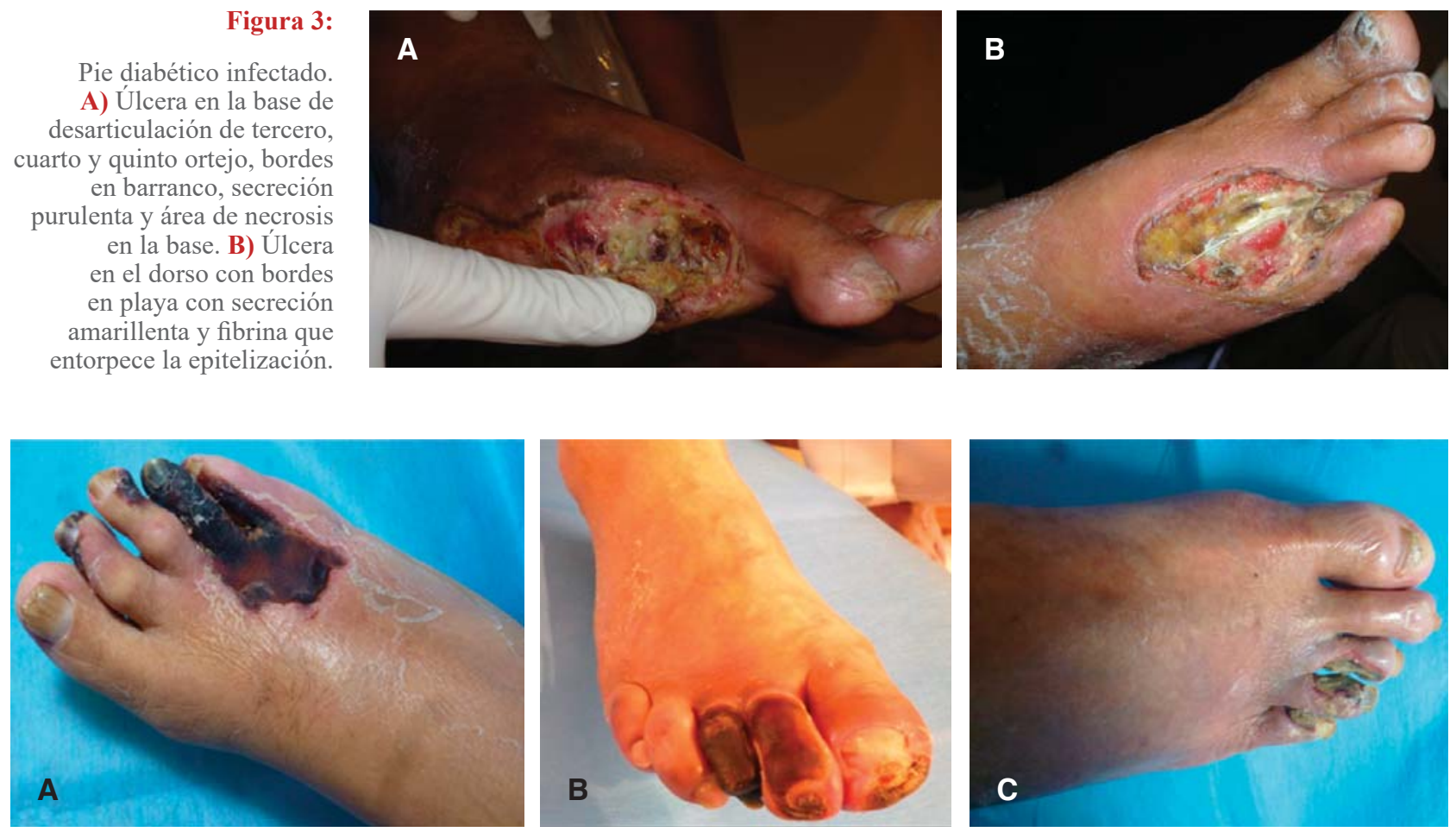

Figura 4: Pie diabético isquémico infectado. A) Isquemia del segundo, tercero, cuarto y quinto ortejo con necrosis seca del cuarto ortejo del pie derecho. B) Pie isquémico infectado con necrosis del primer ortejo en la cara plantar, segundo ortejo en la cara dorsal y tercer ortejo del pie derecho con necrosis seca completa. C) Pie isquémico con necrosis seca del tercero, cuarto y quinto ortejo del pie derecho. Si los pulsos no se palpan se debe hacer un índice tobillo brazo (ITB) para demostrar la isquemia y sugerir una cirugía que mejora la perfusión.

\section{CONCLUSIONES}

El examen del pie debe considerar alteraciones estructurales, la sobrecarga de peso y el riesgo que existe para lesionarse con un zapato inadecuado que condiciona un trauma repetido dentro de un pie insensible por neuropatía autonómica. Teóricamente la concentración de fuerzas anormales incide sobre una superficie de un pie frágil por el daño sensorial, autonómico y somático, lo cual causa una respuesta inflamatoria local, isquemia tisular local, destrucción del tejido local, formación de grietas, ulceración y potencial infección. La definición práctica, sencilla y de utilidad del concepto de pie diabético debe ampliarse y considerarlo como un síndrome de pie diabético. Debe incluir el pie en riesgo, el pie con úlcera, el pie complicado y el pie con amenaza para preservar la extremidad.

\section{REFERENCIAS}

1. Aguilar-Rebolledo F. Neuropatía diabética: aspectos prácticos, diagnósticos, terapéuticos y medidas profilácticas. Editorial Alfil. $3^{3}$ ed. 2009, México, D.F.
2. Aguilar-Rebolledo F. Neuropatía. Actualidades Manifestaciones clínicas y diagnóstica. Rev Med Fam. 2016;2:38-53.

3. Aguilar RF, Rayo MD. Diabetic neuropathy classification, physiopathology and clinical manifestations Part 1. Rev Med IMSS. 2000;38(2):89-99.

4. Aguilar RF, Teran SJM, Escobedo PJ. The pathogenesis of the diabetic foot ulcer: prevention and management. INTECH Open Access Publisher. 2011;155-178.

5. Amin N, Doupis J. Diabetic foot disease: from the evaluation of the "foot at risk" to the novel diabetic ulcer treatment modalities. World J Diabetes. 2016;(7):153-164.

6. Aguilar FA y col. Pie diabético. Diagnóstico, tratamiento y rehabilitación. Editorial Corinter 2013; México, 2013, 110-125

7. Everett $E$, Mathioudakis N. Update on management of diabetic foot ulcers. Ann N Y Acad Sci. 2018;1411(1):153-165.

8. Lipsky BA, Berendt AR, Cornia PB, et al. 2012 infectious diseases Society of America clinical practice guideline for the diagnosis and treatment of diabetic foot infections. J Am Podiatr Med Assoc. 2013(1):2-7.

9. Naemi R, Chatzistergos P, Sundar L, Chockalingam N, Ramachandran A. Differences in the mechanical characteristics of plantar soft tissue between ulcerated and non-ulcerated foot. J Diabetes Complications. 2016;30(7):1293-1299.

10. Medrano MJ, Cerrato E, Boix R, Delgado-Rodríguez M Factores de riesgo cardiovascular en la población española: metaanálisis de estudios transversales. Med Clin (Barc). 2005;124:606-612. 
11. Walsh JW, Hoffstad OJ, Sullivan MO, Margolis DJ. Association of diabetic foot ulcer and death in a population-based cohort from the United Kingdom. Diabet Med. 2016;33(11):14931498.

12. Khunkaew S, Fernandez R, Sim J. Health-related quality of life among adults living with diabetic foot ulcers: a meta-analysis. Qual Life Res. 2019;28(6):1413-1427.

13. Chen SY, Giurini JM, Karchmer AW. Invasive systemic infection after hospital treatment for diabetic foot ulcer: risk of occurrence and effect on survival. Clin Infect Dis. 2017;64(3):326-334.

14. Khan $T$, Armstrong DG. The musculoskeletal diabetic foot exam. Diabetic Foot J. 2018;21(1):17-28.

Financiamiento: No existió financiamiento para este proyecto. 